\title{
Influence of the scale range width on the determination of the hydraulic conductivity and effective porosity. The case of a porous aquifer in southern italy
}

\author{
Carmine Fallico', Samuele De Bartolo', María Fernanda Rivera-Velásquez², Mario lanchello \\ 'Università della Calabria, Dipartimento di Ingegneria Civile, Via P. Bucci, cubo 42/b, 87036, Rende, Italia. \\ ${ }^{2}$ Universidad Nacional de Chimborazo, Facultad de Ingeniería, Avenida Antonio José de Sucre, \\ EC060104, Riobamba, Ecuador. \\ * Autor para correspondencia/Corresponding author: carmine.fallico@unical.it
}

\section{Influencia de la amplitud del intervalo de escala en la determinación de la conductividad hidráulica y la porosidad efectiva. El caso de un acuífero poroso del sur de italia}

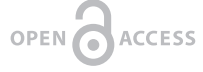

Editado por/

Edited by:

Diego F. Cisneros -

Heredia

Recibido /

Received:

2016-05-25

Aceptado /

Accepted:

2017-02-24

Publicado en línea

Published online:

2018-05-12

\section{Abstract}

The importance of a law that, for an assigned porous medium, gives the variability of the hydraulic conductivity with the effective porosity is well known. Commonly this variability is represented by a power law at different scales, especially those of laboratory and field. Often it can be useful to have a scaling law valid for a single scale range, comprising both those of laboratory and field. Therefore, investigation about the reliability of the laws representing the scaling behavior in the various intervals to which reference was made could be suitable.

The purpose of this study is to provide evidence about the reliability of the scaling laws for laboratory, field and global (laboratory plus field) scaling ranges, verifying consistency with the expected proportionality between hydraulic conductivity and effective porosity for each of these. This verification was carried out using power-type scaling laws to two and four parameters respectively, and performing suitable moving averages of original data sets, in an attempt to reduce the inevitable measurement uncertainties. The experimental results, obtained with reference to the confined aquifer of Montalto Uffugo test field, show that there are no significant differences between the scaling laws considered and highlight the need to reduce the measurement uncertainties, which weigh heavily on the reliability of scaling laws.

Keywords: Scaling law; Hydraulic conductivity; Effective porosity; Laboratory measurement, Field measurement.

\section{Resumen}

La importancia de una ley que, para un dado medio poroso, describa la variabilidad de la conductividad hidráulica en función de la porosidad efectiva es bien conocida. Frecuentemente esta variabilidad está representada por una ley de potencia a diferentes 
escalas, especialmente las de laboratorio y de campo. A menudo es útil tener una ley de escalamiento válida para un cierto rango de escala incluyendo los de laboratorio y campo. Por esta razón, es oportuno investigar la confiabilidad de las leyes que representan este comportamiento de escalamiento en los diferentes intervalos a los cuales típicamente se hace referencia. El propósito de este estudio es proporcionar evidencia sobre la confiabilidad de las leyes de escalamiento para intervalos de escala válidos para laboratorio, campo y globales (laboratorio + campo), verificando la consistencia con la proporcionalidad esperada entre la conductividad hidráulica y la porosidad efectiva para cada uno de estos. Esta verificación se llevó a cabo utilizando leyes de escalamiento de potencia para dos y cuatro parámetros respectivamente, y tratando de reducir las inevitables incertidumbres de medición. Los resultados experimentales obtenidos con referencia al acuífero confinado del campo de prueba Montalto Uffugo, muestran que no hay diferencias significativas entre las leyes de escalamiento consideradas y se destaca la necesidad de reducir las incertidumbres de medición, las cuales tienen un alto peso sobre la fiabilidad de las leyes de escala.

Palabras clave: ley de escalamiento; Conductividad hidráulica; porosidad efectiva; mediciones de laboratorio, medición de campo.

\section{INTRODUCTION}

In the study of the influence that the scale exercises on the variability of the main parameters that characterize a porous aquifer, specific interest is addressed to the hydraulic conductivity and effective porosity, which are the basic parameters for the description of flow and mass transport phenomena. Regarding hydraulic conductivity, it can certainly be asserted that the spatial dependence, although widely tested, still requires further validation [1-13]

Specifically, in the present work the effective porosity was considered instead of the total porosity, taking into account that the motion of the water in the soil is actually influenced from the connectivity and continuity of the pore network [14 - 20]

The causes of the scaling behaviour are generally attributed to medium heterogeneity [21-22]. Moreover, at a different scale, the manner in which the heterogeneity influences the scale behavior is generally different, mainly the shape and size of pores, from small scales and their continuity from larger ones [4,23-24]. This also justifies different scalar behavior at various scales.

Furthermore, according to the specific problem, considering laws of variation at different scales (small, medium, large) for each parameter can be of interest [25].

This has considerable influence on the choice of the measurement methods of the aquifer parameters that must be taken into account in the study of the specific problem. In fact, if the problem requires investigation at very small scale, the parameters can be measured by laboratory tests, whereas if the scale required from the single issue is not 
very small, it is necessary to consider field measurements. These in turn can be of small, medium and large field according to the specific scale to be taken. Indeed, each of the measurement methods of the parameters can involve different aquifer volumes, with even very different techniques, problems, results and reliability [26]. Then it should be noted that relationships can be obtained for an aquifer which express the variability of the hydraulic conductivity $(k)$ vs. the effective porosity $\left(n_{e}\right)$ with reference to the scale of each of the cited investigation fields, namely the laboratory, small, medium and large field (or regional) scale. A single variation law of $k$ with $n_{e}$ valid for all the intervals considered above equally can be obtained for the aquifer considered. However, it is unknown in advance whether it is more appropriate to use single scaling laws, or a single multiple scale law.

The reliability of laws like $k=k\left(n_{e}\right)$, related to the various scale ranges considered, can depend on many factors, such as the number of single data sets, the measurement methods and subsequent implications. It was taken into account that a relation between the hydraulic conductivity and effective porosity characterizing the medium structure is very important and frequently used, because it allows avoidance of expensive and time-consuming analysis and measurements [20,27 - 32]. It is also undeniable that to be able to use a single relationship between $k$ and $n_{e^{\prime}}$ valid for the whole scaling ranges of possible employment, can be considered more advisable.

On the type and the most suitable mathematical representation of the examined parameters scaling laws it was already discussed in previous studies [33,35]. Specifically, Fallico et al. (2016) [34] proposed a not homogeneous power law model, to investigate the possible dependence upon more than a scale. These authors clarified also that a simple (homogeneous) power law model can be adopted for large values of the scale parameter, while for small values of this the inhomogeneous power law model should be used, in agreement with the concept of representative elementary volume [35].

Therefore, the purpose of this study consists in verifying whether the results obtained using scaling laws valid only for individual ranges of interest are more or less reliable than those obtained by the use of a single multiple scaling law, valid for the whole aquifer.

For this purpose, the porous confined aquifer of Montalto Uffugo (Italy) test field was considered and several sets of hydraulic conductivity $(k)$ and effective porosity $\left(n_{e}\right)$ values, obtained by several different laboratory and field measurement methods, were used.

Based on that, the experimental scaling laws of $k=k(s)$ and $n_{e}=n_{e}(s)$ were determined, where $s$ is the scale, relating primarily to the field and the total or multiple experimental scales and comparisons between this last and the first were performed.

It was not possible to determine scaling laws for $k$ and $n_{e}$ even for the laboratory measurements, since the scale of the parameter value assumed for these tests and deriving the size of the samples examined was unique.

Similarly, the experimental law $k=k\left(n_{e}\right)$ was determined and similar comparisons among the laboratory scale, the field scale and the total (or multiple) scale were performed. 
Such comparisons were also made by considering the law $k=k$ (ne) in the form specified by Vukovic and Soro (1992) [36], ie taking into account the grain size analysis.

\section{MATERIALS AND METHODS}

\section{Description of the measurement area}

The area where the measurements considered in this study were carried out is located in the South of Italy, in the middle valley of the Crati river, near the town of Montalto Uffugo, North of Cosenza. From the geological point of view this is a recently formed valley, with slightly consolidated conglomeratic and sandy alluvial deposits of the Calabrian epoch. The lithology of this site shows the presence of a covering layer of alluvial deposits, with thickness of about $7 \mathrm{~m}$, followed by a clay layer, with about $4 \mathrm{~m}$ of thickness, and then by a sand and conglomerate formation, reaching about $55 \mathrm{~m}$ of depth from the ground surface, constituted by marine deposits from the Calabrian epoch and a variable, but always significant, percentage of loam in the various levels. Beyond this depth a clay bank of very large thickness is encountered. The clay layer separating the shallow alluvial deposits from the underlying formation of sand and conglomerates gives locally rise to two aquifers, one shallow and one confined between the clay of this layer and that of the powerful bench constituting the substrate.

The test field is located in this area, which has 11 wells and two piezometers. The 5 wells, marked with even numbers, are related to the surface unconfined aquifer, while the remaining 6 wells, marked with odd numbers, are related to the deeper confined one. Among the latter, only the well No. 11 is fully penetrating, reaching a depth of $57 \mathrm{~m}$ from the ground level and going for about $2 \mathrm{~m}$ into the bottom clay, while the other five are partially penetrating, with a depth of 40 meters below ground level. The wells are arranged in two orthogonal arrays (North-South and East-West), with the well No. 5 located at the intersection and the other wells $10 \mathrm{~m}$ away from this center. The two piezometers $A$ and $B$ are both fully penetrating. The piezometer $A$ is intermediate between the wells No. 1 and No. 5, while the piezometer B is intermediate between the wells No. 5 and No. 9. Further clarifications about the arrangement of the wells are provided by Fig. 1, where a schematic stratigraphy of the test field is also shown. The altitude of the well-top above sea level, the depth from the ground level, and the screen length of each well relative to the confined aquifer are summarized in Table 1.

Figure 1: Planimetrical layout of the wells and piezometers and stratigraphic schematization of the test field.

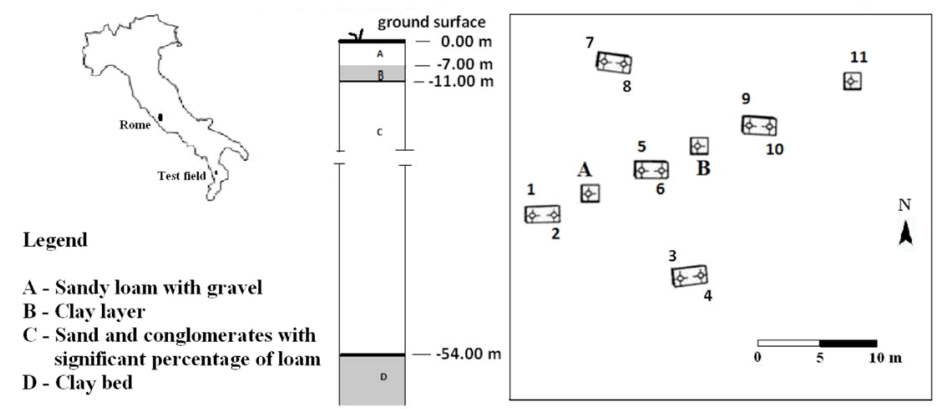


Table 1: Identification number, depth from the ground level and screen length of each well and piezometer relative to the confined aquifer.

\begin{tabular}{|c|c|c|c|c|c|c|c|c|}
\hline & \multicolumn{9}{c}{ Wells } \\
\hline No. & $\mathbf{1}$ & $\mathbf{3}$ & $\mathbf{5}$ & $\mathbf{7}$ & $\mathbf{9}$ & $\mathbf{1 1}$ & \multicolumn{1}{c|}{ A } & B \\
\hline $\begin{array}{c}\text { Well -top } \\
\text { altitude (m a.s.l.) }\end{array}$ & 154.76 & 154.78 & 154.74 & 154.68 & 154.77 & 154.53 & 155.00 & 154.85 \\
\hline $\begin{array}{c}\text { Depth (m) } \\
\text { Screen length } \\
\text { (m) }\end{array}$ & 40 & 40 & 40 & 40 & 40 & 57 & 55 & 55 \\
\hline
\end{tabular}

\section{Methodology and data description}

A hydrogeological process can be considered scaling when the spatial distribution of the considered parameter varies as a power-law [37-40].

Really it is not possible to exclude the possibility of interpretation of these scaling behaviors by other law types, however only the power law was here considered, represented by relations of the following type:

$$
X=a \cdot s^{m}
$$

where $X$ is the examined parameter (as hydraulic conductivity [LT-1 ${ }^{-1}$ or effective porosity $[-]$ ), $s$ is the scale parameter (as the scale representative dimension [L] or its correspondent aquifer volume $\left[\mathrm{L}^{3}\right]$ ), a parameter related to the heterogeneity of medium with the same dimensions as $X$, and $m$ scaling index, which takes into account the fluid-flow type in porous media and the effective dimensions of the measurement scale [41].

In the present investigation only two scale ranges were considered, namely a laboratory scale and field scale, in an attempt to limit the number of the examined parameter measurements, which is necessary to characterize the individual scales adequately. Therefore, it was experimentally verified for $k_{h}$ and for $n_{e}$ the existence of a scalar behavior for both laboratory and field measurements. A similar test was carried out considering a single, total (laboratory + field) scaling range for the parameters investigated.

On the basis of the acquired data, the same procedure was followed to verify experimentally the variation law of the hydraulic conductivity with the effective porosity to the scale taken into consideration, namely those of the lab, field and total, taking always into account power laws, represented by the equation (1).

To determine experimentally the variation law of $\boldsymbol{k}$ with $n_{e}$ using the relation (1), with regard to the different scaling ranges considered in this investigation it was necessary to acquire data for each of these ranges. This required the use of measurement methods of $k$ and $n_{e^{\prime}}$ suitable to investigate aquifer volumes characterized by scaling values within the individual ranges considered. Moreover, to determine experimentally only one law $k=k\left(n_{e}\right)$, to describe the scaling behavior of each parameter for both laboratory and field scale, it was necessary to verify whether the data taken into account for each considered scaling range resulted homogeneous and comparable. This remark concerns mainly the hydraulic conductivity. In fact, while the measurements at field scale provide horizontal 
hydraulic conductivity values $\left(k_{h}\right)$, those of laboratories, carried out on undisturbed soil samples, determine the vertical hydraulic conductivity $\left(k_{v}\right)$, which is generally lower than the horizontal [32,42-45]. This can be attributed, even in the absence of stratification, to a greater compacting of the soil and which encourages the horizontal flow capacity rather than the vertical within the porous media. Therefore, to make the values of hydraulic conductivity $\left(k_{v}\right)$ measured in the laboratory homogeneous and comparable with those measured in the field, the corresponding $k_{h}$ values were determined by the anisotropy coefficient $\left(\mu=\sqrt{\frac{k_{v}}{k_{h}}}\right)[35,46]$ using the following relationship:

$$
k_{h}=\frac{k_{v}}{(\mu)^{2}}
$$

Generally, the $k_{h}$ values obtained in this way, corresponding to those of $k_{v}$ measured in the laboratory, are still lower than those measured in the field and this can be attributed to the scaling effect. In this regard, the studies reported in the literature show situations that are very different. For example, by field measurements [47] obtained $k_{h}$ values from 10 to 1000 times greater than those measured in the laboratory. Indeed, the hydraulic conductivity values so determined in the laboratory are affected even by other uncertainties, according mainly to the level of soil cohesion [31-32,45].

However, the field measurements also show uncertainties due to different factors, according to the measurement type considered [26,48- 50]. Investigation of other uncertainties related to laboratory and field measurements, consequent on the type of porous medium and the measurement modes, cannot be discussed here, although all possible precautions to prevent or at least reduce them were taken during the measurements. However, it can be assumed that these uncertainties, affecting both types of laboratory and field measurements, do not adversely affect the homogeneity of the data sets related to the two corresponding scaling ranges. On this basis a comparison between data corresponding to these scaling ranges can be carried out, verifying the actual influence of the scaling effect and, therefore, of the different ways in which the heterogeneity of the porous medium affects the measurements of the parameters investigated, and excluding influences arising from the use of different data measurement methods.

Moreover, taking into account the widely observed convenience in the use of grain size analysis for the determination of the hydraulic conductivity [27 - 29] [32], the relation $k=k(I)$, where $I$ represents the characteristic parameters of grain size, was also expressed in the form specified by Vukovic and Soro (1992) [36], represented by the following equation:

$$
k=\frac{g}{v} C f(n) d_{e}^{2}
$$

where $k$ is the hydraulic conductivity of saturated porous media [ $\left.\mathrm{LT}^{-1}\right], g$ the acceleration of gravity $\left[\mathrm{LT}^{-2}\right], v$ the kinematic viscosity $\left[\mathrm{L}^{2 T^{-1}}\right], C$ a general coefficient $[-], n$ the total porosity [-], $f(n)$ the porosity function which defines the relationship between the real and modeled porous media, or the degree of material compactness, and $d_{e}$ the effective grain diameter [L]. This general model may be found in numerous commonly used empirical and semi-empirical formulae, showing different governing factors for $k$ [51]. 


\section{Measurements at the Laboratory Scale}

The laboratory measurements were carried out on forty-four undisturbed soil samples, extracted at different depths, between $11 \mathrm{~m}$ and $55 \mathrm{~m}$ from the ground surface, from the drilling columns of two piezometers A ( 27 samples) and B (17 samples). All these samples were subjected to a careful grain size analysis and the meaningful parameter values of soil identification were determined.

The total $(n)$ and effective $\left(n_{e}\right)$ porosity for each of the 44 soil samples were measured by the following respective relationships [52 - 55]

$$
\begin{aligned}
& n=1-\frac{\rho_{\text {bulk }}}{V} \\
& n_{e}=n-\frac{V_{w}}{V}
\end{aligned}
$$

where $\rho_{\text {bulk }}$ is the bulk mass density $\left[\mathrm{ML}^{-3}\right], \rho_{\text {grain }}$ the particle mass density $\left[\mathrm{ML}^{-3}\right], V$ is the total volume $\left[\mathrm{L}^{3}\right]$ and $V_{w}$ the water volume which cannot be drained by gravity $\left[\mathrm{L}^{3}\right]$.

Moreover, the hydraulic conductivity $(k)$ was measured in the laboratory for each of the 44 soil samples previously considered, utilizing flow cells working as constant head per meters. An undisturbed soil sample, saturated previously, was placed in a Plexiglas cell, equipped with a porous membrane at each end to allow the water flow. Each membrane rests on a metal ring, which serves as a support. The water inlet was provided by a plastic tube connecting a Mariotte bottle to the bottom of the cell, whereas the water outlet was at the top of it. The Mariotte bottle, linked with the cell by the plastic tube, had the role to keep a constant hydraulic head. In this way, the air contained in the soil sample can be removed. The cylindrical cell is $0.15 \mathrm{~m}$ long and has a diameter of $0.064 \mathrm{~m}$. The hydraulic conductivity was measured on saturated soil samples at hydraulic heads between 0.05 and $1 \mathrm{~m}$ (Klute and Dirksen, 1986) [56]. The measurements were repeated three times on each sample, assigning different hydraulic heads, for a total of 132 measurements of $k$. For each sample, the mean value of the $\boldsymbol{k}$ measurements was taken as representative.

Therefore, the manner in which the measurements by flow cells was carried out required that the hydraulic conductivity values obtained in this way are referred to the vertical flow, namely they represent the vertical hydraulic conductivity $\left(k_{v}\right)$. Furthermore, the aquifer volume involved in the measurement can be assumed equal to that of the cylindrical sample with the same dimensions as the flow cell.

\section{Measurements at Field Scale}

A total of 35 field measurements were carried out on the confined aquifer of Montalto Uffugo test field; 15 of these measurements were carried out by slug tests, 5 by tracer tests and 15 by pumping tests. The field data sets considered in this investigation, constituted by $k_{h}$ and $n_{e}$ values, are the same already used in a previous work [20]. Therefore, here one refers to the cited study for the salient aspects concerning the data acquisition modalities and for further explanation.

Generally, it can be stated that the slug tests involve in the measurement quite modest aquifer volumes, so commonly they can be referred to a small field scale. Similarly, it can be 
stated that the pumping tests make reference to medium and large field scales, since greater aquifer volumes are involved in the measurements. The tracer tests carried out in the field refer generally to an intermediate scale, that of a medium-field; although they can overlap the scaling intervals characterizing the other measurement methods considered here.

\section{RESULTS AND DISCUSSION}

Regarding the laboratory measurements, the grain size analysis allowed to determine for each examined soil sample the percentages of clay, silt and sand, the effective grain diameters $d_{10}$ and $d_{60}$ (respectively the particle size for which $10 \%$ and $60 \%$ of the sample are finer than) [L] and the coefficient of grain uniformity $\left(U=\frac{d_{60}}{d_{10}}\right)[-]$. These values are
shown in Table 2 .

Table 2: Mid-point depth of the undisturbed soil samples examined in laboratory and relative meaningful results and parameters of the grain size analysis.

\begin{tabular}{|c|c|c|c|c|c|c|c|c|c|c|c|c|c|c|c|}
\hline \multicolumn{8}{|c|}{ Drilling column Piezometer A } & \multicolumn{8}{|c|}{ Drilling column Piezometer B } \\
\hline $\begin{array}{c}\text { Sample } \\
\text { n. }\end{array}$ & $\begin{array}{c}\text { Depth } \\
(\mathrm{m})\end{array}$ & $\begin{array}{c}\text { Clay } \\
\%\end{array}$ & $\begin{array}{c}\text { Silt } \\
\%\end{array}$ & $\begin{array}{c}\text { Sand } \\
\%\end{array}$ & $\begin{array}{c}\mathrm{d} 60 \\
(\mathrm{~mm})\end{array}$ & $\underset{(\mathrm{mm})}{\mathrm{d} 10}$ & $\begin{array}{c}\mathrm{U}= \\
\mathrm{d} 60 / \\
\mathrm{d} 10\end{array}$ & $\begin{array}{c}\text { Sample } \\
\text { n. }\end{array}$ & $\begin{array}{c}\text { Depth } \\
(\mathrm{m})\end{array}$ & $\begin{array}{c}\text { Clay } \\
\%\end{array}$ & $\begin{array}{c}\text { Silt } \\
\%\end{array}$ & $\begin{array}{c}\text { Sand } \\
\%\end{array}$ & $\begin{array}{c}\mathrm{d} 60 \\
(\mathrm{~mm})\end{array}$ & $\begin{array}{c}\mathrm{d} 10 \\
(\mathrm{~mm})\end{array}$ & $\begin{array}{l}\mathrm{U}= \\
\mathrm{d} 60 / \\
\mathrm{d} 10\end{array}$ \\
\hline 1 & 13.65 & 9.3 & 31.2 & 56.8 & 0.12 & 0.004 & 30.00 & 1 & 11.90 & 3.5 & 16.5 & 77.8 & 0.4 & 0.025 & 16.00 \\
\hline 2 & 14.15 & 7.2 & 23.3 & 63.5 & 0.27 & 0.003 & 93.10 & 2 & 12.40 & 2.8 & 12.2 & 77.8 & 0.7 & 0.023 & 30.43 \\
\hline 3 & 15.05 & 8.5 & 27.6 & 62,3 & 0.14 & 0.005 & 28.00 & 3 & 13.30 & 3.2 & 16.8 & 80.0 & 0.4 & 0.015 & 26.67 \\
\hline 4 & 15.90 & 6.8 & 28.7 & 63.1 & 0.29 & 0.007 & 41.4 & 4 & 14.50 & 4.9 & 17.1 & 78.0 & 0.42 & 0.009 & 44.68 \\
\hline 5 & 16.65 & 9.6 & 28.9 & 60.5 & 0.17 & 0.002 & 70.83 & 5 & 18.25 & 3.7 & 21.3 & 70.8 & 0.64 & 0.009 & 71.11 \\
\hline 6 & 17.85 & 16.7 & 45.7 & 37.6 & 0.05 & 0.001 & 51.00 & 6 & 22.95 & 5.8 & 11.2 & 80.0 & 0.63 & 0.059 & 10.68 \\
\hline 7 & 18.92 & 5.4 & 22.9 & 67.5 & 0.28 & 0.005 & 56.00 & 7 & 25.65 & 3.7 & 16.5 & 77.3 & 0.23 & 0.006 & 38.33 \\
\hline 8 & 19.45 & 4.9 & 23.5 & 68.7 & 0.28 & 0.009 & 31.11 & 8 & 29.80 & 2.8 & 12.9 & 81.4 & 0.28 & 0.039 & 7.18 \\
\hline 9 & 20.30 & 5.6 & 22.3 & 69.9 & 0.27 & 0.004 & 67.50 & 9 & 34.65 & 2.3 & 9.3 & 80.6 & 0.68 & 0.084 & 8.10 \\
\hline 10 & 21.60 & 5.6 & 22.2 & 70,0 & 0.28 & 0.004 & 70.00 & 10 & 38.75 & 2.5 & 6.0 & 85.0 & 0.24 & 0.026 & 9.23 \\
\hline 11 & 22.80 & 4.8 & 19,0 & 72,7 & 0.27 & 0.015 & 18.00 & 11 & 41.00 & 4.5 & 8.0 & 80.0 & 0.53 & 0.048 & 11.04 \\
\hline 12 & 24.35 & 4.5 & 21.7 & 70.9 & 0.33 & 0.006 & 55.00 & 12 & 42.75 & 4.2 & 7.6 & 86.7 & 0.53 & 0.071 & 7.46 \\
\hline 13 & 25.50 & 4.2 & 23,2 & 69,4 & 0.30 & 0.006 & 50.00 & 13 & 44.15 & 1.0 & 8.8 & 89.4 & 0.44 & 0.073 & 6.03 \\
\hline 14 & 27.15 & 3.5 & 16.1 & 80.0 & 0.22 & 0.020 & 11.00 & 14 & 47.60 & 3.1 & 10.6 & 81.1 & 0.70 & 0.026 & 26.92 \\
\hline 15 & 29.70 & 6.8 & 17.2 & 71.3 & 0.29 & 0.006 & 48.33 & 15 & 49.75 & 2.6 & 11,5 & 82.8 & 0.50 & 0.039 & 12.82 \\
\hline 16 & 32.25 & 4.3 & 20.7 & 71.7 & 0.27 & 0.006 & 45.00 & 16 & 51.05 & 7.2 & 8.1 & 70.8 & 0.78 & 0.010 & 78.00 \\
\hline 17 & 34.75 & 3.7 & 17.4 & 71.3 & 0.40 & 0.012 & 33.33 & 17 & 52.65 & 2.8 & 6.2 & 91 & 0.23 & 0.004 & 57.50 \\
\hline 18 & 37.50 & 3.5 & 19.3 & 72.2 & 0.25 & 0.007 & 36.71 & & & & & & & & \\
\hline 19 & 40.65 & 6.5 & 27.1 & 65.4 & 0.24 & 0.004 & 61.54 & & & & & & & & \\
\hline 20 & 42.80 & 2.5 & 25.5 & 70.5 & 0.25 & 0.009 & 27.78 & & & & & & & & \\
\hline 21 & 44.25 & 1.3 & 8.6 & 88.1 & 0.40 & 0.060 & 6.67 & & & & & & & & \\
\hline 22 & 45.50 & 2.4 & 28.3 & 66.7 & 0.23 & 0.008 & 28.75 & & & & & & & & \\
\hline 23 & 47.12 & 6.2 & 13.8 & 74.0 & 0.72 & 0.010 & 72.00 & & & & & & & & \\
\hline 24 & 48.05 & 2.1 & 23.1 & 67.8 & 0.70 & 0.009 & 77,78 & & & & & & & & \\
\hline 25 & 49.65 & 2.8 & 14.0 & 82.3 & 0.26 & 0.020 & 13.00 & & & & & & & & \\
\hline 26 & 50.95 & 3.5 & 14.6 & 81.0 & 0.25 & 0.025 & 10.00 & & & & & & & & \\
\hline 27 & 52.80 & 5.0 & 15.0 & 79.0 & 0.18 & 0.029 & 6.21 & & & & & & & & \\
\hline $\begin{array}{l}\text { Mean } \\
\text { values }\end{array}$ & - & -- & -- & - & 0,28 & 0,011 & 42,224 & $\begin{array}{l}\text { Mean } \\
\text { values }\end{array}$ & - & -- & - & - & 0,49 & 0,033 & 27,187 \\
\hline
\end{tabular}


These values show that the samples are composed mainly of sand. Often silt is a considerable portion of the samples. The amount of clay in most of the samples was found to be negligible and only for some of these was it significant.

The measurements carried out in the laboratory on 44 undisturbed soil samples by flow cells allowed the corresponding values of vertical hydraulic conductivity $\left(k_{v}\right)$ to be determined. Equation (2) was used to obtain the corresponding $k_{h}$ values. The value of the anisotropy coefficient $(\mu)$ for the considered aquifer was determined as the average of these parameter values obtained in correspondence to the test field wells, according to the method suggested by Fallico et al. (2002) [57] and by Fallico and Troisi (2003) [58]. The values of $\mu$ determined by these authors in correspondence to the wells No. 1, 3, 5, 7 and 9 of the test field are shown in Table 3. Thus the mean value $\mu=0.37$ was taken for the whole aquifer in question; consequently, the $k_{h}$ value was determined for each soil sample examined. Therefore, the horizontal hydraulic conductivity values obtained by laboratory measurements were considered sufficiently homogeneous, namely comparable with those measured in the field.

Table 3: Values of $\mu$ for observation wells №. 1, 3, 5, 7 and 9 [57-58].

\begin{tabular}{|cc|}
\hline Well No. & $\boldsymbol{\mu}$ \\
\hline 1 & 0.34 \\
\hline 3 & 0.45 \\
\hline 5 & 0.51 \\
7 & 0.22 \\
\hline 9 & 0.33 \\
\hline
\end{tabular}

The data sets of $k_{h}$ and $n_{e}$ relative to the laboratory tests and field tests were separately considered. Moreover, for these parameters other data sets, consisting of the data obtained both in laboratory and in field, were analyzed. Each of the data sets considered was subjected to careful statistical analysis to characterize suitably the parameters $k_{h}$ and $n_{e}$. Therefore, the minimum (min), maximum (max), mean, median values and the variance (VAR), standard deviation (SD), standard error (SE), variation coefficient (VC), Skewness and Kurtosis were estimated [59] for each data set. The values of these statistical parameters, with the data number $(N)$ of each set are shown in Table 4 . A similar statistical analysis was previously performed on the data sets obtained by each field measurement method taken into account (i.e. slug, pumping and tracer tests) and the results are reported in previous studies [20]. 
Table 4: Meaningful statistical parameter values characterizing the considered data sets of hydraulic conductivity $\left(k_{h}\right)$ and effective porosity $\left(n_{e}\right)$.

\begin{tabular}{c|c|c|c|c|c|c|}
\multicolumn{2}{c}{} & \multicolumn{5}{c}{$k_{h}(\mathbf{m} / \mathbf{s})$} \\
\cline { 2 - 7 } Parameters & $\begin{array}{c}\text { Laboratory } \\
\text { tests }\end{array}$ & $\begin{array}{c}\text { Field tests } \\
\text { (Slug+ } \\
\text { Tracer+Pump.) }\end{array}$ & $\begin{array}{c}\text { Lab.+Field } \\
\text { tests }\end{array}$ & $\begin{array}{c}\text { Laboratory } \\
\text { tests }\end{array}$ & $\begin{array}{c}\text { Field tests } \\
\text { (Slug+ } \\
\text { Tracer+Pump.) }\end{array}$ & $\begin{array}{c}\text { Lab.+Field } \\
\text { tests }\end{array}$ \\
\hline N & 44 & 35 & 79 & 44 & 35 & 79 \\
Min & $7,13 \cdot 10^{-7}$ & $1,63 \cdot 10^{-6}$ & $7,13 \cdot 10^{-7}$ & $1,00 \cdot 10^{-2}$ & $4,50 \cdot 10^{-2}$ & $1,00 \cdot 10^{-2}$ \\
\hline Max & $3,48 \cdot 10^{-6}$ & $6,00 \cdot 10^{-6}$ & $6,00 \cdot 10^{-6}$ & $5,00 \cdot 10^{-2}$ & $9,77 \cdot 10^{-2}$ & $9,77 \cdot 10^{-2}$ \\
Mean & $1,63 \cdot 10^{-6}$ & $3,59 \cdot 10^{-6}$ & $2,50 \cdot 10^{-6}$ & $2,39 \cdot 10^{-2}$ & $6,98 \cdot 10^{-2}$ & $4,42 \cdot 10^{-2}$ \\
median & $1,45 \cdot 10^{-6}$ & $3,28 \cdot 10^{-6}$ & $2,29 \cdot 10^{-6}$ & $1,95 \cdot 10^{-2}$ & $6,25 \cdot 10^{-2}$ & $4,20 \cdot 10^{-2}$ \\
VAR & $6,52 \cdot 10^{-13}$ & $1,64 \cdot 10^{-12}$ & $2,04 \cdot 10^{-12}$ & $1,15 \cdot 10^{-4}$ & $2,56 \cdot 10^{-4}$ & $7,01 \cdot 10^{-4}$ \\
\hline SD & $8,08 \cdot 10^{-7}$ & $1,28 \cdot 10^{-6}$ & $1,43 \cdot 10^{-6}$ & $1,07 \cdot 10^{-2}$ & $1,60 \cdot 10^{-2}$ & $2,65 \cdot 10^{-2}$ \\
SE & $1,22 \cdot 10^{-7}$ & $2,17 \cdot 10^{-7}$ & $1,61 \cdot 10^{-7}$ & $1,62 \cdot 10^{-3}$ & $2,71 \cdot 10^{-3}$ & $2,98 \cdot 10^{-3}$ \\
VC & $4,96 \cdot 10^{-1}$ & $3,57 \cdot 10^{-1}$ & $5,71 \cdot 10^{-1}$ & $4,49 \cdot 10^{-1}$ & $2,30 \cdot 10^{-1}$ & $5,99 \cdot 10^{-1}$ \\
\hline Skewness & $8,33 \cdot 10^{-1}$ & $4,02 \cdot 10^{-1}$ & $7,76 \cdot 10^{-1}$ & 1,05 & $4,15 \cdot 10^{-1}$ & $4,88 \cdot 10^{-1}$ \\
\hline Kurtosis & $-4,05 \cdot 10^{-1}$ & $-1,17$ & $-2,35 \cdot 10^{-1}$ & $-1,24 \cdot 10^{-2}$ & $-1,34$ & $-9,97 \cdot 10^{-1}$ \\
\hline
\end{tabular}

The smallest value of the minimum for both the hydraulic conductivity and the effective porosity belongs to the data set of laboratory tests, while the highest value of the maximum belongs to the data set of field tests. Specifically, with reference only to the data obtained by laboratory tests, the variation range amplitude of the $k_{h}$ values is $2.77 \times 10^{-6} \mathrm{~m} / \mathrm{s}$, while that of the variation range of the corresponding $n_{e}$ values is $4.00 \times 10^{-2}$.

This shows that the variations of $n_{e}$ and $k_{h^{\prime}}$ measured along the drilling columns of the piezometers $\mathrm{A}$ and $\mathrm{B}$, result contained in a fairly limited range. Consequently, the presence of significant stratifications over the entire thickness of the considered aquifer can be excluded. This influenced the choice to exclude those field measurement methods used specifically for stratified or strongly inhomogeneous soils.

The mean and median values for both $k_{h}$ and $n_{e}$ show the minimum value for the data sets of the laboratory tests and the maximum for the data sets of the field tests. Moreover, the minimum variance (VAR) is related to the laboratory data set for both these parameters, and the maximum to the cumulative data set, including all laboratory and field data; the same is true also for the standard deviation (SD). The minimum value for the standard error (SE) is, for both $k_{h}$ and $n_{e}$ parameters, related to the respective laboratory data sets, while the maximum value is relative for $k_{h}$ to the field data set and for $n_{e}$ to cumulative data set. The variation coefficient (VC), for both $k_{h}$ and $n_{e^{\prime}}$ shows the minimum value for the field data set and the maximum value for the cumulative (laboratory plus field) data set.

The comparison between the mode and the mean values of each considered data set gives the corresponding Skewness values, which are positive for all the data sets considered, with $k_{h}$ maximum value related to laboratory data set and for $n_{e}$ related to cumulative (laboratory plus field) data set. The corresponding values of Kurtosis are negative for all the data sets considered, indicating distributions with more flattened shape than that of the Gaussian law. 
The $k_{h}$ and $n_{e}$ scaling behavior for the confined aquifer of the Montalto Uffugo test field was already verified in previous studies $[8,20]$

The variation of $k_{h}$ and $n_{e}$ with scale and that of $k_{h}$ with $n_{e}$ were investigated by considering separately the corresponding data sets related to the laboratory, field and total scale and obtaining the relative scaling laws.

Therefore, the relative experimental laws provided by the equation (1) were determined, considering as a scale parameter $(s)$ the radius of influence $(R)$ and the corresponding volume $(V)$ of the aquifer involved in the measurements. The values of $R$ and $V$, determined for each of measurement type considered, are shown in Table 5. The $R$ and $V$ values for the 5 Tracer tests considered are different each other, but since their respective variability ranges are quite contained, it was decided to take for these parameters the corresponding average values.

The corresponding values of the characteristic parameters $a$ and $m$ are shown, for each of the scaling laws obtained, in Table 6. In this table the values of the coefficients of determination $\left(\mathrm{R}^{2}\right)$, relating to each of the experimental scaling law considered, are also shown.

Table 5: Values of the scale parameters $R$ and $V$ for each field measurement method considered.

\begin{tabular}{|c|c|c|c|c|}
\hline \multicolumn{3}{|c|}{ Measurement methods } & $R(\mathrm{~m})$ & $V\left(m^{3}\right)$ \\
\hline \multicolumn{3}{|c|}{ Laboratory measurements } & 0.032 & $4.82 \times 10^{-4}$ \\
\hline \multirow{18}{*}{ 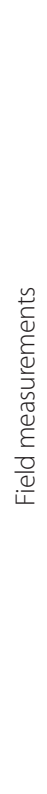 } & \multirow{2}{*}{ Slug tests } & well no. 11 & 28.10 & 109093 \\
\hline & & piezometers $\mathrm{A}$ and $\mathrm{B}$ & 14.10 & 27468 \\
\hline & \multicolumn{2}{|c|}{ Tracer tests (mean values) } & 51.28 & 363245 \\
\hline & \multirow{15}{*}{\multicolumn{2}{|c|}{ Aquifer tests }} & 341.39 & 16102895 \\
\hline & & & 112.60 & 1751775 \\
\hline & & & 154.65 & 3304321 \\
\hline & & & 40.17 & 222939 \\
\hline & & & 278.74 & 10734478 \\
\hline & & & 69.08 & 659395 \\
\hline & & & 216.17 & 6456143 \\
\hline & & & 380.53 & 20005994 \\
\hline & & & 191.84 & 5084645 \\
\hline & & & 313.25 & 13557392 \\
\hline & & & 281.03 & 10911581 \\
\hline & & & 195.45 & 5277809 \\
\hline & & & 316.90 & 13874802 \\
\hline & & & 185.90 & 4774645 \\
\hline & & & 120.10 & 1992821 \\
\hline
\end{tabular}

Obviously it was not possible to obtain a scaling law for laboratory measures, because the dimensions of the individual soil samples, then $R$ and $V$, were all the same. The values 
shown in Table 6 show that the parameter $a$ has lower values for the scaling law relating to the field scale, inducing to believe that the total scale law, which also takes account of the laboratory measurements, is mostly influenced by heterogeneity. On the contrary, the values of the scaling index $m$ are higher for the scaling law relating to the field scale. The values of the parameters $\boldsymbol{a}$ and $\boldsymbol{b}$ of Table 6 show, also, that for $n_{e}$ the relationships obtained respectively for the field and total scales are nearly coincident, even if the value of $R^{2}$ for that to total scale is significantly greater than that to field scale. Indeed, the $R^{2}$ value for the scaling law of $n_{e}$ for the field scale is not such as to be able to state with certainty the existence of a scalar behavior. However, it should be noted that the higher $R^{2}$ values obtained in the present investigation concern precisely the scaling law of $n_{e^{\prime}}$ although for multiple scale. As regards $k_{h^{\prime}}$ the greatest values $\mathrm{R}^{2}$ were obtained, however, for the field scaling law, although the coefficient of determination values remains sufficiently high even for the total scale law. The logarithmic graphs of Fig. 2 and Fig. 3, both assuming $R$ as scale parameter, show the best fitting curve relative to all the $k_{h}$ data sets considered, namely that relative to both laboratory and field measurement values and also that relative only to field measurement values.

Table 6: Values of $a$ and $m$ coefficients of the scaling law (1) for $k_{h}$ and $n_{e}$ respectively to field scale and total scale and relative coefficients of determination.

\begin{tabular}{|c|c|c|c|c|c|c|c|}
\hline \multirow{2}{*}{$\begin{array}{l}\text { Scaling } \\
\text { range }\end{array}$} & \multirow{2}{*}{$\begin{array}{c}\text { Scaling } \\
\text { law }\end{array}$} & \multicolumn{3}{|c|}{ Scale parameter $R$} & \multicolumn{3}{|c|}{ Scale parameter $V$} \\
\hline & & $a$ & $m$ & $\mathbf{R}^{2}$ & $a$ & $m$ & $\mathbf{R}^{2}$ \\
\hline \multirow{2}{*}{ Field scale } & $k_{h}=a \cdot s^{m}$ & $1 \cdot 10^{-6}$ & 0.245 & 0.833 & $7 \cdot 10^{-7}$ & 0.122 & 0.833 \\
\hline & $n_{e}=a \cdot s^{m}$ & 0.038 & 0.149 & 0.577 & $2.66 \cdot 10^{-2}$ & 0.074 & 0.577 \\
\hline \multirow{2}{*}{ Total scale } & $k_{h}=a \cdot s^{m}$ & $2 \cdot 10^{-6}$ & 0.139 & 0.798 & $2 \cdot 10^{-6}$ & 0.052 & 0.729 \\
\hline & $n_{e}=a \cdot s^{m}$ & 0.039 & 0.145 & 0.872 & $3.48 \cdot 10^{-2}$ & 0.056 & 0.860 \\
\hline
\end{tabular}

Figure 2: Trend of $k_{h}$ versus scale for laboratory + field data set and for field data set, with corresponding $95 \%$ confidence intervals.

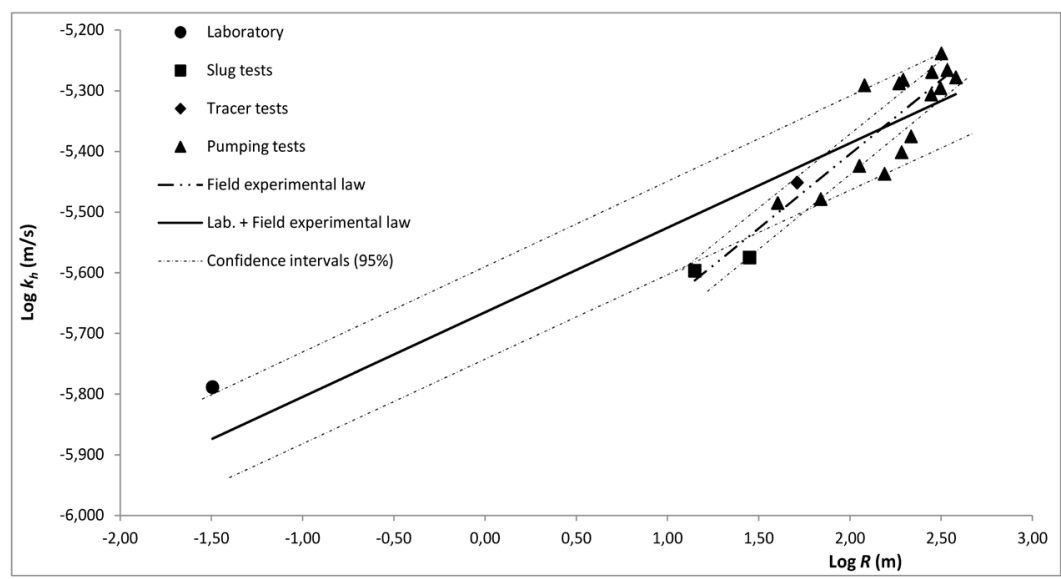


Figure 3: Trend of $n_{e}$ versus scale $(R)$ for laboratory + field data set and for field data set, with corresponding $95 \%$ confidence intervals.

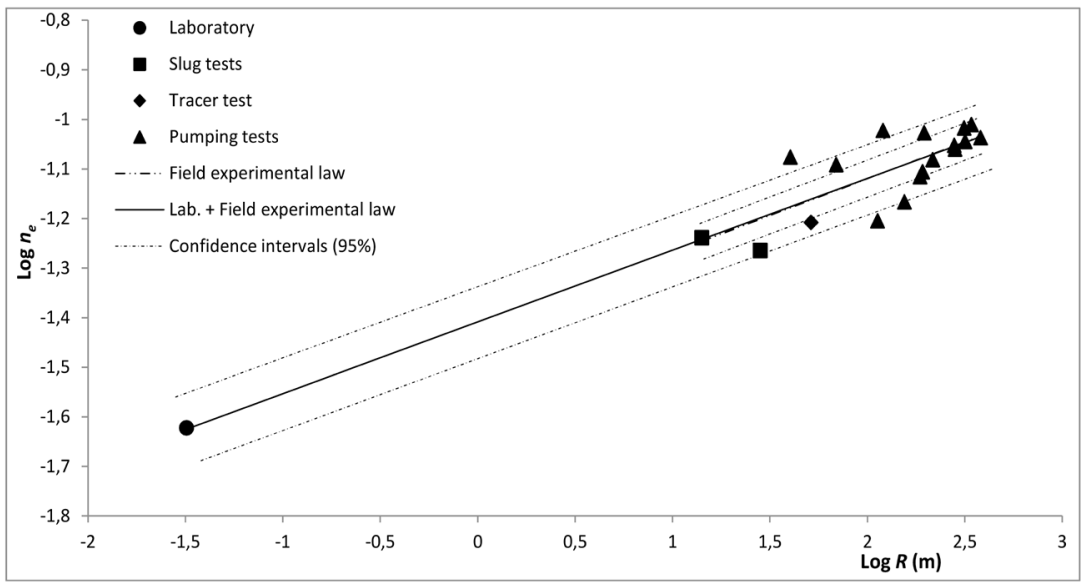

In these figures the 95\% confidence intervals are also shown for each fitting curve (Yevjevich, 1972). The scaling behavior $k_{h}$ was also investigated with the variation of $n_{e^{\prime}}$ considering separately the data sets relative to laboratory scale, field and total scale, and obtaining the corresponding scaling laws. Specifically, considering always relations represented by (1), for laboratory scale the following equation was obtained:

$$
k_{\mathrm{h}}=3.9 \cdot 10^{-5} \cdot n_{e}^{0.853}
$$

that defines the best fitting curve of the corresponding experimental values with a coefficient of determination equal to $R^{2}=0.913$. Similarly, for the field scale the best fitting curve of the corresponding experimental values was defined by the following equation:

$$
k_{h}=8.8 \cdot 10^{-5} \cdot n_{e}^{1.190}
$$

with a determination coefficient equal to $R^{2}=0.980$.

Finally, considering a total scale, the best fitting curve relative to laboratory and field experimental values, was defined by the following equation:

$$
k_{h}=3.9 \cdot 10^{-5} \cdot n_{e}^{0.861}
$$

and the coefficient of determination is equal to $R^{2}=0.960$.

The $R^{2}$ values show that the scaling behavior of $k_{h} v s n_{e}$ can be considered clearly defined for all the scaling ranges here considered. Specifically, the laboratory scale shows the lowest $R^{2}$ value, while the field scale the largest. The total scale, namely for laboratory + field scaling range, has an intermediate $R^{2}$ value, slightly lower compared to that of the field scale.

In Fig. 4 the best fitting curves relating to experimental data sets for the investigated scales are shown. On the same graph the logarithmic 95\% confidence intervals, 
corresponding to the scaling laws expressed by the relations respectively (6), (7) and (8), are shown. The Fig. 4 confirms the low reliability of the scaling behavior described by the equation (6) for the laboratory scale. Moreover, this figure shows a high reliability degree of the scaling behavior expressed by the equation (8), which takes into account a total scale, comprising also that of the laboratory. This latter scaling law describes also acceptably the scaling behavior of $k_{h}$ vs $n_{e}$ in field scale, even if the equation (7), specifically relating to this scaling range, shows a slightly higher value of $R^{2}$.

Figure 4: Trend of $k_{h}$ versus $n_{e}$ for laboratory + field data set, for laboratory data set and for field data set, with corresponding $95 \%$ confidence intervals.

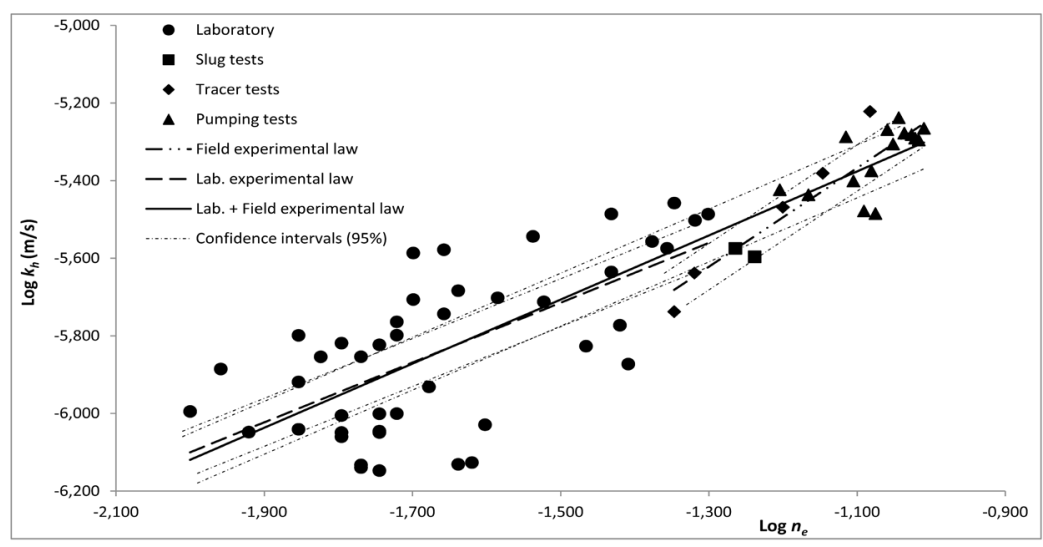

Taking into account that the grain size analysis is certainly a good simplified method to characterize the soil hydraulic properties, the experimental laws (6), (7) and (8) were also proposed in the form represented by the equation (3), following the model of Vukovíc and Soro (1992) [37]. Therefore, for the laboratory scale the equation (6) can also be written in the following form:

$$
k_{h}=\frac{g}{v} \cdot 1.5 \cdot 10^{-2} \cdot n_{e}^{0.853} \cdot d_{10}^{2}
$$

Similarly, for the field scale the relation (7) can also be represented by the following equation:

$$
k_{h}=\frac{g}{v} \cdot 2.36 \cdot 10^{-2} \cdot n_{e}^{1.190} \cdot d_{10}^{2}
$$

so also for the global scale the equation (8) can be represented by the following relationship

$$
k_{h}=\frac{g}{v} \cdot 1.05 \cdot 10^{-2} \cdot n_{e}^{0.861} \cdot d_{10}^{2}
$$

where $d_{10}$ is the particle size for which $10 \%$ of the sample are finer than $[L]$ and the meaning of other symbols was already specified. The equations (9), (10) and (11) can be considered reliable for sandy-loam soils, with $6.03<U<93.10$ and $0.001 \mathrm{~mm}<d_{10}<0.084 \mathrm{~mm}$. These 
relationships allow to obtain, for the corresponding scaling ranges, the $k_{h}=k_{h}\left(n_{e}\right)$ scaling law, varying the $d_{10}$ values in each range investigated by grain size analysis.

In conclusion, the use of scaling laws allows to determine easily the parameters of interest in an expeditious and sufficiently precise manner, avoiding further costs and long times due to tests and analysis, not always simple. The use of a number of laws in function of different scaling ranges is certainly less convenient than to the use of a single law, relative to a total scaling range, with general validity, which may include all the scaling ranges considered. Specific laws, valid into single and limited scaling ranges, generally provide more reliability, than the use of a single, total scaling law. However, if the reliability decrease occurring in such cases is falling within the acceptable limits, the convenience and the consistency of the results leads to justify and, even, prefer the use of a total scaling law than the use of different single laws, valid for limited scaling ranges.

Several studies on the scaling characterization of the hydraulic conductivity and the effective porosity showed that this behavior can be investigated by power law. Therefore the $k_{h}=k_{h}(s), n_{e}=n_{e}(s)$ and $k_{h}=k_{h}\left(n_{e}\right)$ scaling laws were determined. With particular reference to the variation of $k_{h}$ vs $n_{e^{\prime}}$ this research matter falls within the so-called homogeneous behavior of the power law, associated with hydraulic conductivity and effective porosity measurements. This scaling was investigated in specific ambits of the scaling measurements, namely those of the laboratory and of the field.

Furthermore, the data relating to the three different scales taken into account were also analyzed by the grain size analysis, obtaining corresponding relationships that allow a remarkable ease of use even only on the basis of the soil particle size.

\section{ACKNOWLEDGEMENTS}

The authors are grateful to the Editor, who agreed to publish the present study, and to the technical staff of the University of Calabria, who contributed to the experimental phase of the investigation.

\section{CONTRIBUTIONS}

The authors declare to have contributed equally in setting of this study, in performing experimental laboratory and field phases, in processing and verification of data, and in writing the text. 


\section{REFERENCES}

[1] Clauser, C. (1992). Permeability of crystalline rocks. EOS, Trans. Am. Geophys. Union 73:233Y238.

[2] Sánchez-Villa, X., Carrera, J., and Girardi, J. P. (1996). Scale effects in transmissivity. J. Hydrol. 183:1Y22.

[3] Butler, J. J. Jr., and Healey, J.M. (1998). "Relationship between pumping test and slug-test parameters: scale effect or artifact?" Ground Water, vol. 36, no. 2, pp. 305-313.

[4] Giménez, D., Rawls, W. J., and Lauren, J. G. (1999). "Scaling properties of saturated hydraulic conductivity in soil," Geoderma, vol. 88, no. 3-4, pp. 205-220.

[5] Neuman, S. P., and Di Federico, V. (2003). "Multifaceted nature of hydrogeologic scaling and its interpretation". Rev. Geophys. 41:4.1Y4.31.

[6] Martinez-Landa, L., and Carrera, J. (2005). "An analysis of hydraulic conductivity scale effects in granite (Full-scale Engineered Barrier Experiment (FEBEX), Grimsel, Switzerland)," Water Resources Research, vol. 41, no. 3.

[7] Illman, W. A. (2006). "Strong field evidence of directional permeability scale effect in fractured rock," Journal of Hydrology, vol. 319, no. 1-4, pp. 227-236.

[8] Fallico, C., Vita, M. C., De Bartolo, S., and Straface, S. (2012). "Scaling Effect of the Hydraulic Conductivity in a Confined Aquifer". Soil Science, vol. 177(6): 385-391.

[9] Vesselinov, V. V., and Neuman, S. P. (2001). "Numerical inverse interpretation of single-hole pneumatic tests in unsaturated fractured tuff," Ground Water, vol. 39, no. 5, pp. 685-695.

[10] IIIman, W. A. (2005). "Type curve analyses of pneumatic single-hole tests in unsaturated fractured tuff: direct evidence for a porosity scale effect"Water Resources Research, vol. 41, no. 4, pp. 1-14.

[11] Le Borgne, T., Bour, 0., Paillet, F. L and Caudal, J.P. (2006). "Assessment of preferential flow path connectivity and hydraulic properties at single-borehole and cross-borehole scales in a fractured aquifer," Journal of Hydrology, vol. 328, no. 1-2, pp. 347-359.

[12] Fallico, C., De Bartolo, S., Troisi, S. and Veltri, M.(2010). "Scaling analysis of hydraulic conductivity and porosity on a sandy medium of an unconfined aquifer reproduced in the laboratory". Geoderma. 160:3Y12.

[13] Jiménez-Martínez, J., Longuevergne, L., Le Borgne, T., Davy, P., Russian, A., and Bour, 0. (2013). “Temporal and spatial scaling of hydraulic response to recharge in fractured aquifers: Insights from a frequency domain analysis," Water Resources Research, vol. 49, no. 5, pp. 3007-3023.

[14] Serra, 0. (1984). "Fundamentals of Well Log Interpretation", Vol. 1: The Acquisition of Logging Data, Elsevier, Amsterdam, The Netherlands.

[15] Ahuja, L. R., Naney, J. W., Green, R. E., and Nielsen, D. R. (1984). "Macroporosity to characterize spatial variability of hydraulic conductivity and effects of land management" Soil Science Society of America Journal, vol. 48, no. 4, pp. 699-702.

[16] Franzmeier, D. P. (1991). “Estimation of hydraulic conductivity from effective porosity data for some Indiana soils," Soil Science Society of America Journal, vol. 55, no. 6, pp. 1801-1803.

[17] Timlin, D. J., Ahuja, L. R., Pachepsky, Y., Williams, R. D., Gimenez, D., and Rawls, W. (1999). “Use of Brooks-Corey parameters to improve estimates of saturated conductivity from effective porosity," Soil Science Society of America Journal, vol. 63, no. 5, pp. 1086-1092.

[18] Flint, L. E., and Selker, J. S. (2003). "Use of porosity to estimate hydraulic properties of volcanic tuffs," Advances in Water Resources, vol. 26, no. 5, pp. 561-571.

[19] Hantush, M. S. (1964). "Hydraulics of wells". In Chow, V.T., Vol. 1, ed. Advances in Hydroscience. Academic Press, New York, 281-433.

[20] Aimrun, W., Amin, M. S. M., and Eltaib, S. M. (2004). "Effective porosity of paddy soils as an estimation of its saturated hydraulic conductivity," Geoderma, vol. 121, no. 3-4, pp. 197-203

[21] Carrera, J. (1993). "An overview of uncertainties in modelling groundwater solute transport" Journal of Contaminant Hydrology, vol. 13, no. 1-4, pp. 23-48. 
[22] Schulze-Makuch, D., and Cherkauer, D. S. (1997). "Method developed for extrapolating scale behavior," Eos, Transactions American Geophysical Union, vol. 78, no. 13, 3, 7 pages.

[23] Mallants, D., Mohanty, B. P., Vervoort, A., and Feyen J. (1997). "Spatial analysis of saturated hydraulic conductivity in a soil with macropores," Soil Technology, vol. 10, no. 2, pp. 115-131

[24] Knudby, C., and Carrera, J. (2006). "On the use of apparent hydraulic diffusivity as an indicator of connectivity," Journal of Hydrology, vol. 329, no. 3-4, pp. 377-389.

[25] Pacheco, F.A.L., Landim, P.M.B., and Szocs, T. (2015). "Bridging hydraulic diffusivity from aquifer to particle-size scale: a study on loess sediments from southwest Hungary". Hydrological Sciences Journal, vol. 60, no. 2, pp.: 269-284

[26] Zlotnik, V.A., Zurbuchen, B.R., Ptak, T., Teutsch, G. (2000). "Support volume and scale effect in hydraulic conductivity: experimental aspects". In: Zhang, D., Winter, C.L. (Eds.), Theory Modeling and Field Investigation in Hydrogeology: A Special Volume in Honor of Shlomo P. Neuman's 60th Birthday. Geol. Soc. Am. Spec. Pap., 348. Boulder, Colorado, pp. 191-213.

[27] Alyamani, M. S., and Sen, Z. (1993). "Determination of hydraulic conductivity from complete grain-size distribution curves," Ground Water, vol. 31, no. 4, pp. 551-555.

[28] Regalado, C. M., and Muñoz-Carpena, R. (2004). "Estimating the saturated hydraulic conductivity in a spatially variable soil with different permeameters: a stochastic Kozeny-Carman relation," Soil and Tillage Research, vol. 77, no. 2, pp. 189-202.

[29] Odong, J. (2007). "Evaluation of empirical formulae for determination of hydraulic conductivity based on grain-size analysis," The Journal of American Science, vol. 3, no. 3, pp. 54-60.

[30] Song, J., Chen, X., Cheng, C., Wang, D., Lackey, S., and Xu, Z. (2009). "Feasibility of grain-size analysis for determination of vertical hydraulic conductivity of streambeds", J. Hydrol. 375:428-437.

[31] Pliakas, F., and Petalas, C. (2011). "Determination of Hydraulic Conductivity of Unconsolidated River Alluvium from Permeameter Tests, Empirical Formulas and Statistical Parameters Effect Analysis", Water Resour Manage 25:28772899.

[32] Vienken, T., and Dietrich, P.(2011). "Field evaluation of methods for determining hydraulic conductivity from grain size data," Journal of Hydrology, vol. 400, no. 1-2, pp. 58-71.

[33] Fallico, C.(2014). "Reconsideration at field scale of the relationship between hydraulic conductivity and porosity. The case of a sandy aquifer in south Italy". The Scientific World Journal, Vol. 2014, Article ID 537387, 15 pages, http://dx.doi. org/10.1155/2014/537387.

[34] De Bartolo, S., Fallico, C., and Veltri, M. (2013). "A Note on the Fractal Behavior of Hydraulic Conductivity and Effective Porosity for Experimental Values in a Confined Aquifer", The Scientific World Journal, Vol. 2013, Article ID 356753, 10 pages, http://dx.doi.org/10.1155/2013/356753

[35] Fallico, C., De Bartolo, S., Veltri, M., and Severino, G. (2016). “On the dependence of the saturated hydraulic conductivity upon the effective porosity through a power law model at different scales". HYDROLOGICAL PROCESSES, Published online in Wiley Online Library

[36] Bear, J. (1979). "Hydraulics of Groundwater". McGraw-Hill, New York.

[37] Vukovic, M., and Soro, A. (1992). "Determination of Hydraulic Conductivity of Porous Media from Grain-Size Composition". Water Resources Publications, Littleton, Colorado, USA.

[38] Murphy, C.P., and Banfield, C.F. (1978). "Pore space variability in a sub-surface horizon of two soils". Journal Soil Sci., 29, pp: 156-166.

[39] Sisson, J.B., and Wierenga, P.J. (1981). Spatial variability of steady-state infiltration rates as a stochastic process". Soil Sci. Soc. Am. J., 45, pp: 699-704.

[40] Feder, J., (1988). Fractals. Plenum, New York.

[41] Rodriguez-Iturbe, I., Vogel, G.K., Rigon, R., Entekhabi, D., Castelli, F., and Rinaldo, A. (1995). “On the spatial organization of soil moisture fields". Geophys. Res. Lett., 22, pp: 2757-2760.

[42] Schulze-Makuch, D., and Cherkauer, D. S. (1998). "Variations in hydraulic conductivity with scale of measurement during aquifer tests in heterogeneous, porous carbonate rocks," Hydrogeology Journal, vol. 6, no. 2, pp. 204-215. 
[43] Campbell, M. D., Starrett, M. S., Fowler, J. D., and Klein, J. J. (1990). "Slug test and hydraulic conductivity," Ground Water Management, vol. 4, pp. 85-99.

[44] Masch, F. D., and Denny, K. J. (1996). "Grain size distribution and its effect on the hydraulic conductivity of unconsolidated sands" Water Resources Research, vol. 2, no. 4, pp. 665-677.

[45] Cashman, P. M., and Preene, M. (2001). Groundwater Lowering in Construction. A Practical Guide, Spon, New York, NY, USA.

[46] Kalbus, E., Reinstorf, F. and Schirmer, M. (2006). "Measuring methods for groundwater — surface water interactions: a review," Hydrology and Earth System Sciences, vol. 10, no. 6, pp. 873-887e

[47] Herzog, B.L., Griffin, R.A., Stohr, C.J., Follmer, L.R., Morse, W.J. and Su, W.J. (1989). "Investigation of Failure Mechanisms and Migration of Organic Chemicals at Wilsonville, Illinois". Ground Water M.R., Vol. 9, No. 2, pp.:82-89.

[48] Butler, J. J. Jr., McElwee, C. D., and Liu, W. (1996). "Improving the quality of parameter estimates obtained from slug tests" Ground Water, vol. 34, no. 3, pp. 480-490.

[49] Butler, J. J. Jr. (1997). "The Design, Performance, and Analysis of Slug Tests", Kansas Geological Survey—The University of Kansas, Lewis Publishers.

[50] Shapiro, A. M., and Hsieh, P. A. (1998). "How good are estimates of transmissivity from slug tests in fractured rock?". Ground Water, Vol. 36(1): 37-48.

[51] Odong, J. (2007). "Evaluation of empirical formulae for determination of hydraulic conductivity based on grain-size analysis," The Journal of American Science, vol. 3, no. 3, pp. 54-60.

[52] Lambe, T.W. (1951). Soil Testing for Engineers, John Wiley \& Sons, New York, NY, USA.

[53] Danielson, R. E., and Sutherland, P. L. (1986). "Porosity," in Methods of Soil Analysis — Part 1. Physical and Mineralogical Methods", Agronomy Monograph no. 9, pp. 443-461, Soil Science Society of America, Madison,Wis, USA.

[54] Ahuja, L. R., Cassel, D. K., Bruce, R. R., and Barnes, B. B. (1989). "Evaluation of spatial distribution of hydraulic conductivity using effective porosity data," Soil Science, vol. 148, no. 6, pp 404-411.

[55] Staub, M., Galietti, B., Oxarango, L., Khire, M. V. and Gourc, J. P. (2009). "Porosity and hydraulic conductivity of MSW using laboratory - scale tests," in Proceedings of the 3rd International Workshop "Hydro-Physico-Mechanics of Landfills", Braunschweig, Germany.

[56] Klute, A. and Dirkesen, C. (1986). "Hydraulic conductivity and diffusivity: laboratory methods," in Methods of Soil Analysis, Part I, Physical and Mineralogical Methods, A. Klute, Ed., American Society of Agronomy, Madison,Wis, USA, 2nd edition.

[57] Fallico, C., Mazzuca, R., and Troisi, S. (2002). "Determination of Confined Phreatic Aquifer Anisotropy", Ground Water. Vol. 40, №. 5, pp. 475 - 480.

[58] Fallico, C., and Troisi, S. (2003). "Experimental verification of confined phreatic aquifer anisotropy", Proceedings XXX IAHR Congress, 24 - 29 August. Thessaloniki - Greece.

[59] Yevjevich, V. (1972). "Stochastic Processes in Hydrology",Water Resources Publications. 